\title{
ANALISIS RASIO PERMODALAN BMT AL IQ-TISHODY MATARAM
}

\author{
Menik Aryani \\ Program Studi Administrasi Pendidikan, FIPP UNDIKMA \\ Email: Menikaryani81@gmail.com
}

\begin{abstract}
This study is entitled "Capital Analysis Ratio of BMT Al Iq-Tishody Mataram" The purpose of this study is to determine the level of sharia health and compliance in the AL-Iqtishody Mataram BMT 2019 on aspects of capital based on cooperative classification standards according to the cooperative ministerial decree and small business and intermediate number 07 / Per / Dep.6 / IV / 2016. Analyze cooperative financial statements based on the Decree of the Minister of Cooperatives and Small and Medium Enterprises Number 07 / Per / Dep.6 / IV / 2016, Evaluate the financial performance of cooperatives. This study uses 1 type of assessment of health aspects and components in the form of: Capital. The assessment will find out how healthy Al Iq-tishody BMT is in terms of finance, and how obedient in predetermined sharia principles. From these calculations the BMT Al Iq-tishody was classified as "Fairly Healthy" Cooperative. This is because it has an unfavorable value because BMT AL-Iqtishody does not yet have a sharia supervisory board, does not yet have equity participation and financing originating from Islamic financial institutions and also cooperative management does not yet have an educational certificate for management of Islamic financial institutions issued by competent parties.
\end{abstract}

Keywords: Capital, Sharia Health and Sharia compliance

Abstrak: Penelitian ini berjudul "Analisis Rasio Permodalan BMT Al Iq-tishody Mataram” tujuan dari penelitian ini adalah untuk mengetahui tingkat kesehatan dan kepatuhan syariah di BMT AL- Iqtishody Mataram tahun 2019 pada aspek permodalannya berdasarkan standar klasifikasi koperasi menurut surat keputusan menteri koperasi dan usaha kecil dan menengah nomor 07/Per/Dep.6/IV/2016.Melakukan analisis laporan keuangan koperasi dengan berdasarkan Surat Keputusan Menteri Koperasi dan Usaha Kecil Menengah Nomor 07/Per/Dep.6/IV/2016, Melakukan evaluasi kinerja keuangan koperasi. Penelitian ini menggunakan 1 jenis penilaian terhadap aspek dan komponen kesehatan yaitu berupa: Permodalan,. Penilaian tersebut akan mengetahui seberapa sehat BMT Al Iqtishody dalam hal keuangan, dan seberapa patuh dalam prinsip syariah yang telah ditentukan. Dari perhitungan tersebut maka BMT Al Iq-tishody digolongkan kedalam Koperasi "Cukup Sehat". Hal ini dikarenakan memiliki nilai yang kurang baik karena BMT AL-Iqtishody belum memliki dewan pengawas syariah, belum memiliki modal penyertaan dan pembiayaan yang berasal dari lembaga keuangan syariah dan juga manajemen koperasi belum memiliki sertifikat pendidikan pengelolaan lembaga keuangan syariah yang dikeluarkan dari pihak yang kompeten.

\section{Kata kunci : Permodalan, Kesehatan Syariah dan kepatuhan Syariah}

\section{LATAR BELAKANG}

Wacana mengenai ekonomi syariah khususnya pembentukan lembaga keuangan syariah disingkat LKS sedang dan sudah marak dilakukan di indonesia. Lembagalembaga keuangan yang ada mulai berbenah diri agar sesuai dengan prinsip-prinsip syariah, bahkan sudah ada yang mendahului dengan berdirinya Bank Muamalat Indonesia pada tahun 1992, kemudian diikuti LKS lainnya, seperti Asuransi Syariah, Pasar Modal Syariah, Reksadana Syariah, Pegadaian
Syariah, bahkan Multilevel Marketing Syariah dan Hotel Syariah. Namun dibandingkan dengan LKS lainnya itu, ke beradaan koperasi yang menerapkan 'syariah' relatif ketinggalan gerbong kereta (sangat terlambat), padahal dengan keberadaan jumlah koperasi yang hampir 'ribuan' jumlahnya yang menyebar di seluruh Indonesia dan sebagian besar anggotanya beragama Islam yang menginginkan juga keamanan secara non materi (bebas dari riba dan bunga), masih memungkinkan (berpotensi) untuk 
'mensyariahkan

koperasi'

atau

mengkorvesikan ke dalam koperasi syariah tanpa harus berusaha dari awal ataupun mendirikan koperasi syariah.

Koperasi Jasa Keuangan Syariah (KJKS) adalah lembaga keuangan mikro yang dioperasikan dengan prinsip bagi hasil, menumbuh kembangkan bisnis usaha mikro dalam rangka mengangkat derajat dan martabat serta membela kepentingan kaum fakir miskin, ditumbuhkan atas prakarsa dan modal awal dari tokoh masyarakat setempat dengan berlandaskan pada system ekonomi yang salam keselamatan (berintikan keadilan), kedamaian dan kesejahteraan. Penghimpunan dana diperoleh melalui simpanan pihak ketiga dan penyaluran dilakukan dalam bentuk pembiayaan atau investasi yang dijalankan berdasarkan syariat islam.

Koperasi Syariah mulai diperbincangkan banyak orang ketika menyikapi semaraknya pertumbuhan Baitul Maal Wattamwil di Indonesia. Baitul Maal Wattamwil yang dikenal dengan sebutan BMT yang dimotori pertama kali oleh BMT Bina Insan Kamil tahun 1992 di Jakarta, mampu memberwarna bagi perekonomian kalangan akar rumput yakni para pengusaha mikro.

Lembaga BMT yang memiliki basis kegiatan ekonomi rakyat dengan falsafah yang sama yaitu "dari anggota-anggota untuk anggota" maka berdasarkan Undang-Undang RI Nomor 25 tahun 1992 tersebut berhak menggunakan badan hukum koperasi.letak perbedaannya dengan Koperasi Konvensional (nonsyariah) salah satunya terletak pada teknik operasionalnya saja, Koperasi Syariah mengharamkan bunga dan mengusung etika moral dengan melihat kaidah halal dan haram dalam melakukan usahanya.

Berangkat dari kebijakan pengelolaan BMT yang memfokuskan anggotanya pada sektor keuangan dalam hal penghimpunan dana dan pendayagunaan dana tersebut maka bentuk yang idealnya adalah Koperasi Simpan Pinjam Syari'ah yang selanjutnya disebut KJKS (Koperasi Jasa Keuangan Syari'ah) sebagaimana Keputusan Menteri Koperasi RI No. 91 /Kep/M.KUKM/ IX/2004 tentang Petunjuk Pelaksanaan Kegiatan Usaha Koperasi Jasa Keuangan Syari'ah

Menurut data Dinas Koperasi dan UKM Provinsi NTB tahun 2019 tercatat sebanyak 217 BMT yang sudah berbasis syariah di Provinsi Nusa Tenggara Barat. Di Mataram sebanyak 15 BMT syariah, Lombok Barat sebanyak 31 BMT syariah, Lombok Utara sebanyak 11 BMT syariah, Lombok Tengah sebanyak 38 BMT syariah, Lombok Timur sebanyak 48, Sumbawa Barat sebanyak 12 BMT syariah, Sumbawa sebanyak BMT syariah, Dompu sebanyak 7 BMT syariah, Kabupaten Bima sebanyak 26 BMT syariah, Kota Bima sebanyak 2 BMT syariah dan provinsi sebanyak 16 BMTsyariah.

Pada tahun 2012 BMT Al-iqtishody memperoleh legalitasnya, dengan mendapat Nomor Badan Hukum: 118.45/602/BH/XXVIII.6/KUKM/2012.

Dengan demikian, BMT Al-iqtishody telah memperoleh izin secara legal dari Pemerintah.

Fokus utama BMT Al-iqtishody adalah pelayanan jasa keuangan dibidang usaha Perberdayaan kelompok home industry terhadap masyarakat umum dan anggota pada khususnya.Koperasi syariah Permata Hidayatullah juga memperhatikan kendali mutu dan kendali biaya terhadap provider pelayanan keuangan. Sehingga dapat terwujud peningkatan pelayanan perberdayaan kelompok home industri dengan pola syariah dan biaya yang rasional.

\section{TINJAUAN PUSTAKA}

Pengertian Baitul Maal Wat Tamwil

(BMT) Menurut Peraturan Menteri Negara 
Koperasi dan Usaha Kecil dan Menengah Republik Indonesia Nomor: 35.3/Per/M.KUKM/X/2007 tentang Pedoman Pelaksanaan Penilaian Kesehatan Koperasi Jasa Keuangan Syariah dan Unit Jasa Keuangan Syariah Koperasi, pengertian KJKS adalah lembaga koperasi yang melakukan kegiatan usaha pembiayaan, investasi, dan simpanan berdasarkan pola syariah yang perlu dikelola secara profesional sesuai dengan prinsip kehati-hatian dan kesehatan, sehingga dapat meningkatkan kepercayaan dan memberikan manfaat sebesar-besarnya kepada anggota dan masyarakat di sekitarnya. (Kementerian Koperasi, 2007, hlm.1) Sedangkan Baitul Maal wat Tamwil (BMT) adalah sebuah lembaga keuangan yang berbadan hukum Koperasi Jasa Keuangan Syariah.Di Indonesia lembaga ini belakangan populer seiring dengan semangat umat Islam untuk mencari model ekonomi alternatif pasca krisis ekonomi tahun 1997.Kemunculan BMT merupakan usaha untuk memberdayakan ekonomi masyarakat.BMT memiliki perbedaan dengan lembaga keuangan seperti halnya perbankan.BMT tidak tunduk kedalam aturan perbankan yang ketat, hal ini disebabkan karena BMT tidak berada di bawah naungan Bank Indonesia tetapi di bawah pembinaan Kementerian Negara Koperasi dan UKM, sehingga bersifat fleksibel disesuaikan dengan kondisi di dalam masyarakat.Selain itu karyawan ataupun staf diharuskan mampu berperan aktif, dinamis, kreatif, proaktif, dan tidak menunggu melainkan menjempu pelanggan atau nasabah maupun anggota (Felayaty \& Chadhiq, 2014, hlm.54).

\section{Landasan Koperasi Syariah}

Peraturan Menteri Koperasi dan Usaha Kecil dan Menengah RI tentang Pedoman
Standar Operasional Manajemen Koperasi Jasa Keuangan Syariah.

- Pancasila dan Undang-Undang Dasar 1945.

- Peraturan Mentri Negara Koperasi Dan Usaha Kecil dan Menengah Republik Indonesia Nomor: 16/Per/M.KUKM/IX/2015 tentang aturan mengenai pelaksanaan kegiatan usaha simpan pinjam dan pembiayaan syariah.

- Peraturan Mentri Negara Koperasi Dan Usaha Kecil dan Menengah Republik Indonesia yaitu Peraturan Deputi Bidang Pengawasan Kementrian Koperasi dan Usaha Kecil Dan Menengah Republik Indonesia Nomor: 07/Per/Dep.6/IV/2016 tentang Pedoman Penilaian Kesehatan Koperasi Simpan Pinjam Dan Pembiayaan Syariah Dan Unit Simpan Pinjam Dan Pembiayaan Syariah.

- Koperasi syariah berazaskan gotong royong dan kekeluargaan.

- Koperasi syariah berlandaskan syariah Islam yaitu al-quran dan assunnah dengan saling tolong-menolong (ta'awun) dan saling menguatkan (takaful). (www. Koperasisyariah.com)

\section{Prinsip koperasi syariah}

Menurut Hendrojogi(2008:24).Prinip dasar yang harus dimiliki oleh koperasi syariah adalah sebagai berikut:

1. Kekayaan adalah amanah Allah SWT yang tidak dapat dimiliki oleh siapapun secara mutlak

2. Manusia diberi kebebasan buermuamalah selama bersama dengan ketentuan syariah

3. Manusiamerupakan khalifah Allah dan pemakmur di muka bumi

4. Menjunjung tinggi keadilan serta menolak setisp bentuk riba dan 
pemusatan sumber dana ekonomi pada seglintir orang atau sekelompok orang saja.

5. Keanggotaan bersifat sukarela dan terbuka

6. Keputusan ditetapkan secara musyawarah dan dilaksanakan secara konsisten dan konsekuen.

7. Pengelolaan dilakukan secara transparan dan profesional

8. Pembagian SHU dilakukan secara adil,sesuai dengan besarnya jasa usaha masing-masing anggota.

\section{Produk-Produk Koperasi Syariah}

Menurut Muhammad Ridwan (2004:166), produk-produk koperasi syariah adalah sebagai berikut:

a. Simpanan (Funding): Produk simpanan dibagi menjadi dua berdasarkan prinsipnya. Yaitu simpanan dengan prinsip wadiah dan simpanan dengan prinsip mudhorobah.

b. Pembiayaan (Financing): Berdasarkan pemanfaatannya pembiayaan dibagi menjadi dua yaitu; pembiayaan investasi dan pembiayaan modal kerja. Sedangkan berdasarkan sifatnya dibagi mnjadi dua yaitu; pembiayaan konsumtif dan pembiayaan produktif.

\section{Tingkat Kesehatan BMT}

Penilaian tingkat kesehatan merupakan kegiatan penting bagi perusahaan, karena dengan penilaian tingkat kesehatan tersebut akan dapat diketahui sejauh mana perusahaan (berdasarkan kriteria dan ukuran tertentu) dapat dipandang berhasil atau kurang berhasil dalam menjalankan usahanya. Hasil penilaian tingkat kesehatan tersebut dapat dipergunakan sebagai bahan pertimbangan dan bahkan pedoman guna membenahi, memperbaiki, mengubah, atau menghentikan suatu kebijakan manajemen perusahaan (Sugiyarso, 2011, hlm.130).Sama halnya juga koperasi yang juga salah satu pelaku dalam perekonomian, bahkan mempunyai peranan besar dalam perekonomian rakyat. Oleh karena itu, koperasi agar dapat bersaing dengan perusahaan lain harus dalam kondisi sehat. Untuk kepentingan tersebut, penilaian kesehatan koperasi harus dilakukan secara periodik (Sugiyarso, 2011, hlm.130).Tingkat kesehatan Koperasi Syariah adalah suatu kondisi sebuah yang dinyatakan dalam kategori Sehat, Cukup Sehat, Kurang Sehat, dan Tidak Sehat (Buchori, 2012, hlm.229). Aspek kesehatan BMT secara garis besar dapat dilihat dari dua aspek, yaitu aspek kinerja keuangan, serta kelembagaan dan manajemen: 1. Kinerja Keuangan: BMT mampu melakukan penggalangan, pengaturan, penyaluran, dan penempatan dana dengan baik, teliti, hati-hati, dan benar, sehingga berlangsung kelancaran arus pendanaan dalam pengelolaan kegiatan usaha. 2. Kelembagaan dan Manajemen: BMT memiliki kesiapan untuk melakukan operasinya dilihat dari sisi kelengkapan legalitas, aturanaturan, dan mekanisme organisasi dalam perencanaan, pelaksanaan, pendampingan dan pengawasan, SDM, permodalan, sarana, dan prasarana kerja.

\section{Penilaian Kesehatan Koperasi Syariah}

Menurut Peraturan Mentrian Negara Koperasi Dan UKM RI Tahun 2007 tentangPedoman Penilaian Kesehatan Koperasi Jasa Keuangan Syariah Dan Unit Jasa Keuangan Syariah Koperasi yaitu ruang lingkup penilaian Kesehatan KJKS dan UJKS Koperasi meliputi penilaian terhadap beberapa aspek sebagai berikut :

a. Permodalan;b. Kualitas Aktiva Produktif;c. Manajemen;d. Efisiensi;e. Likuiditas;f. 
Kemandirian dan Pertumbuhan;g. Jatidiri Koperasi; danh. Prinsip Syariah.

Penetapan Kesehatan BMT Berdasarkan hasil penilaian terhadap delapan aspek sebagaimana dimaksud di atas maka diperoleh skor secara keseluruhan.Penetapan predikat kesehatan serupa secara parsial berdasarkan aspek yang dinilai juga dapat dilihat pada masing-masing penilaian aspek yang sudah dijelaskan di atas. Penetapan predikat tingkat kesehatan KJKS dan UJKS Koperasi tersebut adalah sebagai berikut: Penetapan Prediksi Tingkat Kesehatan KJKS Kriteria Tingkat Kesehatan Skor SEHAT $81 \pm 100$ CUKUP SEHAT $66<80$ KURANG SEHAT $51<66$ TIDAK SEHAT $0<51$ Sumber diolah: Peraturan Menteri Negara KUKM $\quad$ RI No 35.3/Per/M.KUKM/X/2007.

\section{METODE PENELITIAN}

\section{Tahapan-Tahapan Penelitian}

Tahapan-tahapan yang akan dilakukan dalam penelitian ini meliputi :

1. Pengumpulan data

Tehnik pengumpulan data yang akan dilakukan dalam penelitian ini adalah melalui observasi dan wawancara.

2. Analisis Data

Untuk menganalisa data-data yang diperoleh dari koperasi digunakan Surat Keputusan Menteri Koperasi Nomor :07/Per/Dep.6/IV/2016 agar dapat dilihat kesehatan koperasi..

3. Melakukan evaluasi kinerja keuangan koperasi

Penelitian ini menggunakan 8 jenis penilaian terhadap aspek dan komponen kesehatan yaitu berupa, Permodalan, Kualitas Aktiva Produktif, Manajemen, Efisiensi, Likuiditas, Kemandirian dan pertumbuhan, Jati Diri Koperasi dan Kepatuhan Prinsip Syariah. Tetapi pada penelitian ini Penilaian hanya focus pada aspek permodalam untuk mengetahui seberapa sehat BMT AL-Iqtishody dalam hal keuangan, dan seberapa patuh dalam prinsip syariah yang telah ditentukan.

\section{Lokasi Penelitian}

Penelitian ini akan dilaksanakan pada BMT AL-Iqtishody yang berkedudukan di Jalan Gajah Mada Pagesangan, Mataram.

\section{Rancangan Penelitian}

Tehnik Pengumpulan Data

Tehnik pengumpulan data yang digunakan adalah :

a. Wawancara

Wawancara merupakan proses untuk memperoleh informasi untuk tujuan penelitian dengan cara Tanya jawab sambil bertatap muka dengan responden. Dalam hal ini peneliti melakukan wawancara terhadap pengurus koperasi untuk mengetahui kegiatan sehari-hari koperasi dan untuk mengumpulkan data yang mendukung penelitian.

b. Observasi

Agar mendapat kevalidan dari data keterangan yang diperoleh setiap lokasi, juga dilakukan observasi.Dari teknik observasi ini data yang diperoleh tentang suasana koperasi, kegiatan-kegiatan koperasi dan grafik-grafik tentang perkembangan keuangan koperasi.Dalam observasi ini peneliti langsung melihat keadaan dilapangan.

c. Dokumentasi

Dokumentasi merupakan salah satu cara pengumpulan data dengan menelusuri data-data historis, baik berupa surat, catatan, laporan, kenang-kenangan, dan lain-lain. Dalam metode ini peneliti mengumpulkan berbagai laporan dan catatan yang relevan dengan tujuan di tahun 2019. 


\section{Analisis Data}

Untuk mengukur kesehatan BMT ALIqtishody pada tahun 2019 maka digunakan standar kesehatan koperasi syariah menurut surat keputusan menteri koperasi dan usaha kecil dan menengah nomor :07/Per/Dep.6/IV/2016.

\section{Hasil dan Pembahasan}

Hasil Penelitian

Aspek Permodalan
Penilaian aspek permodalan dilakukan dengan menggunakan dua rasio permodalan yaitu rasio perbandingan modal sendiri dengan total asset dan rasio kecukupan modal (CAR). Rasio perbandingan modal sendiri terhadap total asset bertujuan untuk mengukur kemampuan koperasi dalam menghimpun modal sendiri dibandingkan dengan asset yang dimiliki. Sedangkan rasio Kecukupan Modal (CAR) dilakukan agar koperasi melakukan pengembangan usaha yang sehat dan dapat menanggung resiko kerugian dalam batasbatas tertentu.

Dari data sekunder yang telah didapat, maka dapat dilihat hasil dari rasio-rasio aspek permodalan pada tabel dibawah ini:

Hasil Perhitungan Rasio Modal Sendiri Terhadap Total Aset Dan Rasio CAR

\begin{tabular}{|c|l|l|c|}
\hline \multirow{2}{*}{ No } & \multicolumn{1}{|c|}{ Nama KSPPS } & \multicolumn{2}{|c|}{ Rasio (\%) } \\
\cline { 3 - 4 } & & $\begin{array}{c}\text { Rasio Modal Sendiri terhadap } \\
\text { total aset }\end{array}$ & CAR \\
\hline 1 & Bmt Al-Istihody & $9,59 \%$ & 8,02 \\
\hline
\end{tabular}

Sumber: Data primer yang diolah

Dari tabel diatas dapat dilihat bahwa BMT AL-Iqtishody memiliki nilai rasio modal sendiri terhadap total aset kurang dari $20 \%$ yang berarti koperasi ini belum dipercaya oleh nasabah dalam menyimpan dana di koperasi tersebut, dan pada rasio kecukupan modal (CAR) koperasi ini memiliki nilai di atas $7 \%$ yang artinya koperasi tersebut cukup sehat. Perhitungan ini menjadi langkah awal dalam melakukan penilaian kesehatan terhadap setiap koperasi.

Penilaian kesehatan atas setiap rasio pada aspek permodalan ini dapat dilihat pada tabel berikut:

Analisis Penilaian Kesehatan-Aspek Permodalan

\begin{tabular}{|c|l|c|c|c|c|c|}
\hline No & \multicolumn{1}{|c|}{ Nama KSPPS } & Rasio & $\begin{array}{c}\text { Nilai } \\
\text { Kredit }\end{array}$ & Bobot & Skor & Predikat \\
\hline 1 & Bmt Al-Istihodya.Rasio & 9,59 & 25 & $5 \%$ & 1,25 & $\begin{array}{c}\text { Tidak } \\
\text { sehat } \\
\text { Modal Sendiri:Total Aset } \\
\text { b.CAR }\end{array}$ \\
& & 8.02 & 100 & $5 \%$ & 5 & $\begin{array}{c}\text { Cukup } \\
\text { sehat }\end{array}$ \\
\hline
\end{tabular}




\section{Total}

6,25

Sumber: Data primer yang diolah

Pada aspek ini BMT AL-Iqtishody mendapatkan skor sebesar 1,25 pada rasio modal sendiri terhadap total aset yang berarti memiliki predikat kurang sehat dan pada rasio kecukupan modal (CAR) mendapatkan skor sebesar 5 yang berartisehat, sehingga pada aspek permodalan ini BMT AL-Iqtishody mendapatkan skor sebesar 6.25. Dilihat dari Laporan Keuangan BMT AL-Iqtishody, permodalan koperasi syariah Permata Hidayatullah mengalami peningkatan, yaitu dari Rp. 127.166.179,00 pada tahun 2016 menjadi Rp.266.101.817,39pada tahun 2017, begitu pula pada sisi aset juga mengalami peningkatan, yaitu sebesar Rp.2.309.696.130,00 pada tahun 2016 menjadi Rp. 2.774.011.157,43pada tahun 2017. Namun peningkatan aset ini tidak sebanding dengan peningkatan modal, sehingga nilai rasio permodalan padaBMT AL-Iqtishody ini masih berada pada predikat cukup baik.

\section{Pembahasan}

Aspek Kepatuhan Prinsip Syariah

Penilaian pada aspek kepatuhan syariah ini dilakukan dengan perhitungan nilai kredit yang didasari pada hasil penilaian atas jawaban pertanyaan sebanyak 10 buah pertanyaan dengan masing-masing bobot $10 \%$ perpertanyaan yang berarti untuk setiap jawaban positif 1 memperoleh nilai kredit bobot 1. Dari pertanyaan pertanyaan pada aspek kepatuhan syariah ini, didapat nilai dari Koperasi Syariah Permata Hidayatullah yang dapat dilihat pada tabel dibawah ini:

\section{Hasil Penilaian Aspek Kepatuhan Syariah}

\begin{tabular}{|l|l|l|l|l|}
\hline No & Nama KSPPS & Tahun & Nilai Kredit Bobot & Kriteria \\
\hline 1 & Al-Istihody & 7 & 7 & Patuh \\
\hline
\end{tabular}

Sumber: Data primer yang diolah

Secara umum BMT AL-Iqtishody telah mematuhi seluruh aspek kepatuhan syariah. Namun dalam penerapannya belum sepenuhnya dilakukan. BMT AL-Iqtishody belum memliki dewan pengawas syariah, belum memiliki modal penyertaan dan pembiayaan yang berasal dari lembaga keuangan syariah dan juga manajemen koperasi belum memiliki sertifikat pendidikan pengelolaan lembaga keuangan syariah yang dikeluarkan dari pihak yang kompeten. Untuk itu disarankan kepada BMT AL-Iqtishody untuk dapat mencari lembaga keuangan syariah untuk dapat mencari modal penyertaan, agar dapat meningkatkan permodalan yang dimiliki dan juga dapat menjadi likuiditas koperasi. BMT ALIqtishody harus membentuk dewan pengawas syariah yang kompeten dan memiliki sertifikat. Selain itu, BMT AL-Iqtishody dapat mengikuti pendidikan dalan pengelolaan lembaga keuangan syariah agar manajemen pengelolaan koperasi semakin baik.

Peringkat Kesehatan Bmt Al-Istihody 


\begin{tabular}{|c|c|c|c|c|c|c|c|c|c|c|c|}
\hline \multirow{2}{*}{$\begin{array}{l}\mathbf{N} \\
\mathbf{0}\end{array}$} & \multirow{2}{*}{$\begin{array}{l}\text { Nama } \\
\text { KSPPS }\end{array}$} & \multicolumn{8}{|c|}{ Aspek Penilaian } & \multirow[t]{2}{*}{ Total } & \multirow[t]{2}{*}{ Predikat } \\
\hline & & $\begin{array}{l}\text { MD } \\
\text { L }\end{array}$ & $\begin{array}{l}\mathbf{K} \\
\mathbf{A P}\end{array}$ & MNJ & $\begin{array}{l}\text { EF } \\
\text { I }\end{array}$ & LIK & JDK & $\mathbf{K P}$ & $\begin{array}{l}\text { KP } \\
\mathbf{S}\end{array}$ & & \\
\hline 1 & $\begin{array}{l}\text { Bmt Al- } \\
\text { Istihody }\end{array}$ & 6,25 & 16 & 12,20 & 7,5 & 13.75 & 8.75 & 7.75 & 7 & 79.20 & $\begin{array}{l}\text { Cukup } \\
\text { Sehat }\end{array}$ \\
\hline
\end{tabular}

Sumber: Data primer yang diolah

Setelah melakukan perhitungan penilaian kesehatan terhadap aspek permodalan didapatkan hasil mengenai tingkat kesehatan Koperasi Syariah Permata Hidayatullah yatu berada pada golongan cukup sehat. Pada perhitungan yang telah dilakukan dan dilihat dari laporan keuangan, secara umum belum mencadangkan dana yang cukup besar untuk pencadangan penghapusan aktiva produktif (PPAP) untuk menghindari risiko yang akan terjadi atas pembiayaan atau piutang yang sulit tertagih. Untuk itu disarankan kepada koperasi-koperasi yang masih mencadangkan dana yang cukup kecil untuk PPAP, agar meningkatkan dana untuk penyisihan penghapusan piutang aktiva produktif dalam kisaran $60-80 \%$ dari total piutang atau pembiayaan kurang lancar atau macet, agar mampu menghindari risiko yang tidak diinginkan saat piutang atau pembiayaan yang sulit tertagih. Pada aspek likuiditas menunjukkan nilai yang kurang baik dikarenakan dana yang diterima oleh koperasi ini masih terbilang kecil untuk dapat memberikan pembiayaan kepada anggota atau kepada masyarakat umum. Sehingga disarankan untuk dapat meningkatkan dana yang diterima oleh koperasi dengan cara melakukan promosi agar anggota koperasi bertambah sehingga dana yang diterima oleh koperasi juga meningkat.

\section{KESIMPULAN}

Berdasarkan hasil analisis penelitian yang dilakukan maka dapat disimpulkan bahwa :
1. Berdasarkan surat keputusan menteri koperasi dan usaha kecil dan menengah nomor :07/Per/Dep.6/IV/2016" maka perhitungan penilaian kesehatan BMT ALIqtishody berdasarkan 8 aspek yaitu aspek permodalan, kualitas aktiva produktif, manajemen, efisiensi, likuiditas, jati diri koperasi, kemandirian dan pertumbuhan dan kepatuhan prinsip syariah

2. Dari perhitungan tersebut maka BMT Al Iq-tishody digolongkan kedalam Koperasi "Cukup Sehat". Hal ini dikarenakan memiliki nilai yang kurang baik karena BMT AL-Iqtishody belum memliki dewan pengawas syariah, belum memiliki modal penyertaan dan pembiayaan yang berasal dari lembaga keuangan syariah dan juga manajemen koperasi belum memiliki sertifikat pendidikan pengelolaan lembaga keuangan syariah yang dikeluarkan dari pihak yang kompeten.

\section{DAFTAR PUSTAKA}

Arthaloka Gf Gd.05,2006. Ekonomi Syariah Lembaga Bisnis Syariah, Jakarta: Pusat Komunikasi.

Alma, Buchari dan Donni Juni Priansa,2009 Manajemen Bisnis Syariah, Bandung: Alfabeta.

Arifin, Zainul, 2005.Dasar-dasar Manajemen Bank Syariah: Pengantar Muhammad Syafii Antonio, Jakarta: Pustaka Alvabet. 
http://www.indonesiastudent.com/pengertiankoperasi-syariah/ akses pada tanggal 15 juni 2017

https://bmtpermatahidatullah.files.wordpress.com/ 2014/05/comp-profil-bmt-permatahidayatullah.pdf akses pada tanggal 3 juni 2017

Ilmi, Makhalul, 2002. Teori \& Praktik Lembaga Mikro Keuangan Syariah, Yogyakarta:UII Press.

Indriantoro, Nur dan Drs. Bambang Supomo, M.Si, Akuntan,2009. Metodologi Penelitian Bisnis: Untuk Akuntansi dan Manajemen, Yogyakarta: BPFE Fakultas Ekonomi UGM.

Muhammad,2000. Lembaga-Lembaga Keuangan Umat (kontemporer), Yogyakarta:STIS.
Ridwan, Muhammad,2004 Manajemen Baitul Maal wa Tamwil (BMT), Yogyakarta:UII Press.

Soemitra, Andri, 2009. Bank dan Lembaga Keuangan Syariah: Go Syariah Trust Your Heart and Falt, Jakarta: Kencana.

Sugiyono, 2009.Metodologi Penelitian Bisnis, Bandung: Alfabeta.

Sumiyanto, Ahmad, 2008.BMT Menuju Koperasi Modern: Panduan untuk Pemilik,Pengelola dan Pemerhati Baitul Maal wat Tamwiil dalam Format Koperasi, Yogyakarta: ISES Publishing.

Yasin, Nur, 2009.Hukum Ekonomi Islam: Geliat Perbankan Syari'ah Indonesia,Malang: UIN Malang

Press. 